\title{
The Impact of Policies to Control Motor Vehicle Emissions in Mumbai, India*
}

\author{
Akie Takeuchi $^{1}$, Maureen Cropper ${ }^{1,2}$, and Antonio Bento ${ }^{1}$
}

\begin{abstract}
World Bank Policy Research Working Paper 4059, November 2006
The Policy Research Working Paper Series disseminates the findings of work in progress to encourage the exchange of ideas about development issues. An objective of the series is to get the findings out quickly, even if the presentations are less than fully polished. The papers carry the names of the authors and should be cited accordingly. The findings, interpretations, and conclusions expressed in this paper are entirely those of the authors. They do not necessarily represent the view of the World Bank, its Executive Directors, or the countries they represent. Policy Research Working Papers are available online at http://econ.worldbank.org.
\end{abstract}

*We thank the World Bank Research Committee and the Transport Anchor for funding, and Alex Pfaff for comments.

\footnotetext{
${ }^{1}$ University of Maryland

${ }^{2}$ World Bank
} 


\section{The Impact of Policies to Control Motor Vehicle Emissions in Mumbai, India}

\section{Introduction}

\section{A. Motivation and Purpose}

Mumbai, like many Indian cities, has a serious air pollution problem caused, at least in part, by mobile sources. Between 2000 and 2002, annual average PM10 was approximately $80 \mu \mathrm{g} / \mathrm{m} 3$ (World Bank 2005), higher than in Mexico City. ${ }^{3}$ In many ways, however, Mumbai is more fortunate than other Indian cities. It has an extensive rail and bus system and a much smaller vehicle fleet than Delhi, a city of comparable size and income. The problem facing Mumbai is to reduce emissions from diesel trucks and buses, as well as taxis and auto-rickshaws - and to prevent rapid growth of the private vehicle fleet. ${ }^{4}$

In this paper we examine the impacts of measures to reduce emissions from passenger transport; specifically, buses, cars and two-wheelers. These include the possibility of converting diesel buses to compressed natural gas (CNG), as the Indian Supreme Court required in Delhi, which would necessitate an increase in bus fares to cover the cost of pollution controls. We also consider raising the price of gasoline, which should affect the ownership and usage of cars and two-wheelers, as well as imposing a license fee on cars, to retard growth in car ownership. The impact of each policy on emissions depends not only on how the policy affects the mode that is regulated, but on shifts to other modes. For example, a "clean bus" policy might actually increase

\footnotetext{
${ }^{3}$ The National Environmental Engineering Research Institute (NEERI) monitors RSPM (respirable particle) levels, which are approximately equivalent to PM10. It should be noted that annual average RSPM has been declining steadily since 1997, largely as a result of the closing of textile mills in the city. ${ }^{4}$ Some measures along these lines have already been taken: by 2003 all highly polluting taxis and autorickshaws were required to be converted to natural gas. The sulfur content of diesel fuel has been reduced from 2500 to $500 \mathrm{ppm}$ (World Bank 2005).
} 
emissions from transport if the increase in bus fares causes enough people to switch to cars and two-wheelers.

Previous attempts to estimate the impacts of pollution control policies from passenger vehicles have focused primarily on controlling emissions from automobiles and relied mostly on U.S. data. A key result in this literature (Eskeland 1995) is that a tax on auto emissions can be mimicked by combining command-and-control measures to reduce emissions per mile with a gasoline tax to reduce vehicle miles traveled. At the margin, the cost of emissions reductions should be the same via the gas tax and pollution controls. Holding the marginal cost of pollution controls constant, a higher percent of the total reduction in emissions will come from a tax on gasoline, the more elastic is the demand for gasoline. Using data from the U.S. Consumer Expenditure Survey, Fullerton and West (2000) calculate the welfare improvement from a zero-tax scenario to the ideal Pigouvian tax, and find that 71 percent of that gain can be achieved by the second-best combination of taxes on gas, engine size, and vintage. A gas tax alone attains 62 percent of the Pigouvian gain.

In countries where the share of ridership in public transit, in particular buses, is high, there is a need to evaluate the impacts of policies that reduce emissions from buses. These can take the form of reducing emissions from diesel buses - for example, by installing particle traps if lower-sulfur diesel fuel is available—or replacing diesel buses with CNG buses. Assuming that bus fares will rise to cover the cost of pollution control measures, a potential adverse effect of these policies may be the switch from public to private transportation, which is likely to entail higher emissions per passenger mile traveled. To our knowledge the only study that examines the effect of mode substitution 
on pollution control policies is Swait and Eskeland's (1995) study of mode choice in São Paolo. They examine the net effect on air pollution of subsidizing bus fares. We examine the related question of whether raising bus fares will, on net, cause substitution to dirtier forms of transport, per passenger mile traveled

\section{B. Approach Taken}

Estimating the impact of pollution control policies that affect the price of travel requires estimating models of mode choice and vehicle ownership. We use data from a survey of 5,000 households in Mumbai, conducted in 2003, to estimate models of commute mode choice and vehicle ownership. The price elasticities obtained from these models are combined with data on passenger-kilometers traveled and emissions per passenger kilometer to compute the impact of policies on emissions from transport. Specifically, we ask:

- How sensitive is private vehicle ownership to a change in purchase price or to a change in the price of gasoline?

- What would be the net effect of a change in the tax on gasoline on emissions from transport in Mumbai?

- How will the requirement that buses be converted to CNG affect bus ridership and vehicle ownership, assuming that it will increase bus fares?

- What would be the net effect on emissions from transport of a policy to convert diesel buses to CNG?

The paper is organized as follows. Section II presents a simple model of the generation of emissions from transport that clarifies the relationship between changes in 
prices, modal shares and emissions. It also presents the stylized facts about the vehicle fleet and emissions from transport in Mumbai. To estimate the impact of a change in (e.g.) the price of gasoline on emissions from transport requires estimating the elasticity of vehicle ownership and usage with respect to the price of gasoline, as well as crossprice elasticities. The models of mode choice and vehicle ownership that we estimate are described in section III, which also describes the data and estimation results. Section IV provides a rough calculation of the net benefits associated with a program to convert diesel buses to CNG in Mumbai.

\section{The Impact of Pollution Control Policies on Emissions from Transport}

This section outlines the simple analytics of the impact of policies to control emissions from passenger vehicles on particulate emissions from transport. Let $E$ be total particulate emissions from transport and $E_{c}$ particulate emissions from commercial vehicles. Let $x_{i}$ denote the aggregate demand for mode $i$ (in passenger kilometers) and $e_{i}$ particulate emissions per passenger kilometer associated with mode $i$. In practice, passenger modes include walking and rail, for which $e_{i}=0$, as well as car, two-wheeler, and bus. Aggregate emissions from transport are given by (1):

$$
E=E_{c}+\sum_{i} x_{i} e_{i}
$$

\section{A. Alternative Pollution Control Policies}

With this simple framework, we can evaluate the impacts of policies aimed at reducing pollution. We consider two policies: an increase in the gasoline tax and the conversion of buses from diesel to CNG. 
In practice, an increase in the tax on gasoline will primarily affect the cost of driving cars and two-wheelers. ${ }^{5}$ If $p_{j}$ denotes the cost of a car, per passenger kilometer traveled, and $p_{k}$ the cost per passenger kilometer of a two-wheeler, then (assuming that $p_{j}$ and $p_{k}$ are proportional to the price of gasoline) the elasticity of emissions, $E$, with respect to a change in the price of gasoline is given by (2):

$$
\frac{\partial E}{\partial p_{\text {gas }}} \frac{p_{\text {gas }}}{E}=\sum_{i} \frac{e_{i} x_{i}}{E}\left[\varepsilon_{i j}+\varepsilon_{i k}\right]
$$

where $\varepsilon_{i j}$ is the elasticity of total passenger kilometers for mode $i\left(x_{i}\right)$ with respect to the price of mode $j$. Note that:

$$
x_{i}=m_{i} *(\text { average trip length })_{\mathrm{i}} *(\text { total number of trips made by all travelers) }
$$

where $m_{i}=$ share of trips made via mode $i$. Assuming that a change in the price of gasoline has no effect on the total number of trips made, or on average trip length, the elasticity of $x_{i}$ with respect to $p_{j}$ is the elasticity of $m_{i}$ with respect to $p_{j}{ }^{6}$

Equation (2) implies that the net effect of a change in the price of gasoline is the sum of two effects: the decline in the share of trips made by cars and two-wheelers (the own-price elasticity effect) and the effect of an increase in the price of gasoline on shifts to other modes (e.g., walking, bus and rail). The net impact of these effects depends on the magnitude of cross-price elasticities of demand, as well as on how polluting substitute modes are.

\footnotetext{
${ }^{5}$ As noted below, regulations are in effect to convert taxis and auto-rickshaws (three-wheelers) to CNG. We therefore focus on the impact of an increase in the price of gasoline on cars and two-wheelers (motorcycles and scooters).

${ }^{6}$ An increase in the price of gasoline should decrease average trip length and the number of trips made; however, our data do not permit us to estimate these effects. Our estimate of the elasticity of passenger kilometers traveled with respect to the price of gasoline is therefore an underestimate of the true elasticity.
} 
To evaluate the impact of a policy to replace diesel buses with CNG buses, with an increase in bus fares to cover the cost of the conversions, let ${ }^{0}$ s denote emissions and passenger kilometers traveled before the program is enacted and ${ }^{1}$ 's denote after-program values. The impact of the program on total emissions from transport is given by (3),

$$
\Delta E=\left(e_{i}^{0} x_{i}^{0}-e_{i}^{1} x_{i}^{1}\right)+\sum_{-i} e_{-i} \frac{\partial x_{-i}}{\partial P_{i}}
$$

where $i$ refers to "bus." Whether the net effect of the clean bus program is to reduce emissions from transport depends on whether an increase in the bus fare induces substitution to other, dirtier modes (per passenger kilometer), such as cars and twowheelers.

\section{B. The Contribution of Various Modes to Transport Emissions in Mumbai}

Calculating the elasticity of emissions from transport with respect to a change in the price of gasoline or a "clean bus" policy requires estimates of the share of emissions attributable to each transport mode $\left(e_{i} x_{i} / E\right)$. In this section we present the stylized facts about the vehicle fleet, vehicle kilometers traveled and the contributions of various types of vehicles to PM10 emissions in Mumbai.

Table 1 presents the 2001 vehicle fleet, estimates of the fraction of VKTs attributable to various segments of the fleet, and the emissions factors used by the National Environmental and Engineering Research Institute (NEERI) in calculating an emissions inventory for Mumbai (NEERI 2004). Two-wheelers and cars constitute three quarters of the vehicle fleet in Mumbai. According to the 2001 Census, $9 \%$ of all 
households own a two-wheeler, while $8 \%$ own a car. These percentages are much lower than in Delhi, where $28 \%$ of households own two-wheelers and $13 \%$ own cars.

The lower rate of vehicle ownership in part reflects Mumbai's extensive rail and bus systems. Mumbai is served by three rail lines, the Western, Central and Harbor, which carry 5 million passengers per day. All trains are electric, and therefore do not contribute to PM emissions in the Greater Mumbai Region (GMR). Mumbai's municipal bus system, which carries 4.5 million passengers each day, is operated by the Brihanmumbai Electric Supply and Transport Undertaking (BEST). Of the 14,500 buses in Mumbai, approximately 3,400 are BEST buses. The remainder are school buses and buses that provide private commuting services. Taxis and auto-rickshaws (three-wheeled vehicles) comprise the remainder of Mumbai's passenger transport system.

Data on vehicle kilometers traveled come from studies conducted by NEERI (2004) to construct a grid-wise emissions inventory for Mumbai, as do the emissions factors listed in Table 1. Estimates of VKTs for each grid cell and vehicle type were constructed from vehicle counts, obtained at different times of day, and estimates of gridwise road length. These, together with emissions factors, were used to estimate annual tons of PM10 emitted in each $2 \mathrm{~km} \times 2 \mathrm{~km}$ grid in the city. The corresponding fraction of PM10 emissions accounted for by each vehicle class are obtained from the grid-wise emissions inventory. Table 1 indicates that, in 2002, diesel vehicles (buses and goods vehicles) contributed $76 \%$ of directly emitted PM10 from transport in Mumbai. ${ }^{7}$ Private

\footnotetext{
${ }^{7}$ According to Burningham (2005) BEST's 3391 buses traveled approximately 240 million km in 20022003. Applying NEERI's emission factor of $3 \mathrm{gm} / \mathrm{km}$ to this mileage yields 720 tons of PM10 emissions.
} 
passenger vehicles (cars and two-wheelers) contributed $15 \%$ of directly emitted PM and taxis and three-wheelers about $9 \%$ of PM10 emissions. ${ }^{8}$

What is being done to control emissions from transport in Mumbai and what remains to be done? As of 2002, all new commercial and non-commercial vehicles must obey Euro II emissions standards. To deal with highly polluting, older vehicles, all taxis over 8 years old are either to be retired or converted to CNG (as of $1 / 1 / 2003$ ), as are highly polluting 3 -wheelers over 8 years of age. All transport vehicles over 8 years old (except BEST buses) are to be retired or converted to CNG, effective 2/1/2004 (World Bank 2005).

Policies that are not included in the above list are requirements to reduce emissions from BEST buses, most of which are diesel, and policies to restrict the ownership and use of cars and two-wheelers. BEST diesel buses could be replaced with CNG buses or diesel buses with diesel oxidation catalysts (DOCs). Vehicle ownership and use could be discouraged by imposing a significant license fee on automobiles; ownership and use could also be discouraged by raising the tax on gasoline. If these policies were implemented in 2005, we would expect the share of emissions from taxis and three-wheelers to differ from those in row 4 of Table 1, assuming that the policies to retire or convert old taxis and three-wheelers are enforced. For this reason, we treat the contribution of taxis and three-wheelers to PM emissions as negligible in computing the share of emissions from different categories of vehicles. This implies that BEST buses account for $15.4 \%$, cars $10.6 \%$, and two-wheelers 5.6\% of the PM10 emissions from transport.

\footnotetext{
${ }^{8}$ According to NEERI the share of PM10 from transport is $32 \%$. It is $45 \%$ from industry, $18 \%$ from area sources, and $5 \%$ from building and road construction.
} 


\section{Models of Vehicle Ownership and Commute Mode Choice}

Calculating the effect of the policies outlined above requires estimates of the price elasticity of demand for passenger transportation. In this section we describe models of mode choice which we estimate to produce short-run price elasticities of demand. In these models we treat the number, origin and destination of trips as fixed, and look at the impact of changes in the time and money costs of travel on mode choice. We also estimate joint models of vehicle ownership and mode choice.

Before presenting the models that we estimate, we examine mode choice in Mumbai. Tables 2 and 3 are based on a survey of 5,000 households in the Greater Mumbai Region conducted by Baker, Basu, Cropper, Lall and Takeuchi (2005). ${ }^{9}$ Table 2 shows the main commute mode ${ }^{10}$ to work for the two most important income earners in each household who work at a fixed location within the GMR. Table 3 shows the main mode used for work and non-work trips, based on travel diaries administered to the main earner in the household, a randomly chosen adult in the household, and a randomly chosen person between 16 and 21.

Several points are worth emphasizing. The first is that work trips constitute almost half of all trips made by adults in Mumbai. Indeed, work trips constitute $67.5 \%$ of all trips when trips are weighted by distance traveled. The second is that over half of all trips in Mumbai are made on foot. Approximately $45 \%$ of work trips are made on foot, and the percentage is even higher for other types of trips. Because our interest from the

\footnotetext{
${ }^{9}$ The Great Mumbai Region is an area of approximately 437 sq. km. whose population in 2001 was 11.9 million. Our analysis applies to the GMR and not to the Mumbai metropolitan area, with a population of over 18 million.

${ }^{10}$ For multiple mode trips, the main mode is defined as the motorized mode in which the traveler spends the longest time. Walking and bicycling can be a main mode only if the trip is single mode trip.
} 
perspective of pollution is in motorized trips, we focus on the journey to work, for which the percent of motorized trips is the highest. ${ }^{11}$

Table 2 indicates that, after walking (44\%), train and public bus are the major modes used in commuting ( $23 \%$ and $16 \%$ respectively). The shares of two-wheelers and cars are small (9\% and 3\% respectively). If we look at higher income groups, however, the share of private vehicles is considerably larger (21\% for two-wheelers and $24 \%$ for cars for household earning more than 20,000 rupees per month). This suggests that, as incomes increase, the demand for private vehicle use would potentially impose a burden on an already crowded city, both in terms of air quality and congestion.

\section{A. The Commute Mode Choice Model}

Holding residential and employment locations fixed, a traveler must decide what mode to use for the journey to work. The mode choice decision can be modeled as a discrete choice problem. Formally, let $V_{m}$ denote the observable portion of the utility that is received from taking mode $m$ and $e_{m}$ the portion of utility known to the traveler but unobserved by the researcher. Typically, $V_{m}$ depends on the time cost of traveling, which is broken into in-vehicle time and out-of-vehicle time (vector $t_{m}$ ); on the money cost of traveling $\left(c_{m}\right){ }^{12}$ and on a mode-specific constant that captures the utility of the mode common to all persons $\left(d_{m}\right)$,

$$
V_{m}=\beta_{d m} d_{m}+\beta_{t}{ }^{\prime} t_{m}+\beta_{c} g\left(c_{m}\right)
$$

\footnotetext{
${ }^{11}$ From a modeling perspective, the work trip has well a defined origin and destination. Most people take one round trip per day, so that there is no need to model trip generation.

${ }^{12} c_{m}$ is the daily round-trip cost of commuting.
} 
In model $1, g\left(c_{m}\right)=c_{m} /$ hourly wage so that $V_{m}$ is the generalized time cost of traveling by mode $m$. In equation (4) $g()$ is the logarithm of daily income minus $c_{m}$, i.e., the logarithm of the Hicksian bundle. Assuming that the $\left\{e_{m}\right\}$ are independently and identically Gumbel distributed, the probability that mode $m$ is chosen is given by the multinomial logit formula

$$
\left.P_{m}=P\left(V_{m}+e_{m}>V_{n}+e_{n}, \forall n \neq m\right)=\exp \left(V_{m}\right) / \sum_{n} \exp \left(V_{n}\right)\right]
$$

In view of the well known limitations of the multinomial logit model, we also estimate a mixed logit model that allow $\beta_{d m}, \beta_{t}$, and $\beta_{c}$ to vary across travelers according to the distribution $F(\boldsymbol{\beta} \mid \theta), \boldsymbol{\beta}=\left\{\beta_{d m}, \beta_{t}, \beta_{c}\right)$ and $\theta$ is parameter that defines the density function. In the mixed logit model the choice probability of mode $m$ becomes

$$
P_{m}=\int\left[\exp \left(\mathrm{V}_{\mathrm{m}}(\beta)\right) / \sum_{n} \exp \left(V_{n}(\beta)\right] d F(\beta) .\right.
$$

We assume that $\beta_{d m}$ normally distributed and that $\beta_{t}$ and $\beta_{c}$ are lognormally distributed and estimate the mixed logit model by hierarchical Bayesian methods.

In estimating the commute mode choice models the worker is assumed to choose a commute mode from the following five options: (1)walking; (2) rail; (3) bus; (4) bus + rail; (5) motorized two-wheeler (MTW); (6) car. Bicycle, auto rickshaw, taxi and shared ride are eliminated due to the very low frequency with which they are observed in the data. The bus + rail option assumes bus access to nearest rail station, followed by travel by rail for the rest of the trip, since most of multi-mode trips are in this form.

The choice set for each traveler is determined by the following rules: (1)The choice set for a given worker excludes two-wheeler and/or car if the household does not own one; (2) Rail and bus + rail are not an option if the nearest rail station to home and 
the nearest station to work are the same; (3) The walking and bus modes enter all commuters' choice sets.

\section{B. A Joint Model of Vehicle Ownership and Commute Mode Choice}

In the medium term, households may choose to purchase a vehicle and thus

change their choice set. We model this process using a nested logit model. At the upper level of the nest the household has four choices of ownership status: (1) own neither a two-wheeler nor a car; (2) own a two-wheeler only; (3) own a car only; (4) own both a two-wheeler and a car. The systematic part of utility the household receives from mode $m$ under nest $n$ is

$$
\mathrm{V}_{\mathrm{nm}}=\beta_{d m} d_{m}+\beta_{d n} d_{n}+\beta_{z n}{ }^{\prime} Z+\beta_{t}{ }^{\prime} t_{m}+\beta_{c} * \ln \left(I-O_{n}-c_{m}\right)
$$

where $d_{n}$ is a nest-specific dummy, $Z$ is a vector of household characteristics, $I$ is household monthly income, $O_{n}$ is the ownership cost of nest $n$, and $c_{m}$ is the cost of commuting to work by mode $m$. All variables in equation (7) refer to the journey to work of the main income earner in the household. The unobserved part of utility $\left\{e_{n m}\right\}$ is distributed

$$
\exp \left(-\sum_{n=1}^{4}\left(\sum_{m \in S_{n}} \exp \left(-e_{n m} / \lambda_{n}\right)^{\lambda_{n}}\right)\right)
$$

and the choice probability is

$$
\mathrm{P}_{\mathrm{nm}}=\exp \left(V_{n m} / \lambda_{n}\right) * \sum_{j \in S_{n}} \exp \left(V_{n j} / \lambda_{n}\right)^{\lambda_{n}-1} / \sum_{k=1}^{4} \sum_{j \in S_{k}} \exp \left(V_{k j} / \lambda_{k}\right)^{\lambda_{k}}
$$


We could allow preference parameters to vary with household characteristics, but as our analysis suggests that it does not make much difference to the computation of elasticities, we keep fixed coefficients for simplicity.

Under each nest, the worker's choice set is generated according to the rules described in the previous section. For example, under nest (1), the commute mode choices available are walk, bus, rail and bus + rail if the worker's residential location is far enough from his work location, while nest (2) contains the choices in nest (1), plus a two-wheeler. In the model of vehicle ownership, some households simply cannot afford some of the options. We assume that if the sum of ownership cost and operating cost exceeds a household's monthly income, the option is not available to the household.

\section{Data}

The data for estimating both sets of models come from our Mumbai household survey (Baker, Basu, Cropper, Lall and Takeuchi 2005). For the mode choice models, journey-to-work data come from the descriptions of the usual commute trips of the two main income earners in the household questionnaire. We asked each respondent to identify the two main income earners in the household and to describe their job locations (in terms of section and pin code), ${ }^{13}$ earnings, and a typical journey to work (modes taken, out-of-vehicle time, in-vehicle time, out-of-pocket cost). Information was reported for 6,666 income earners from 4,979 households. In estimating commute mode choice models the following workers were dropped from the sample: (1) workers with no fixed

\footnotetext{
${ }^{13}$ Mumbai is divided into 88 sections. A commuter's workplace location was considered to be the centroid of the intersection of the section and pincode (analogous to zip code) in which he worked. The geographic coordinates of residential locations were recorded for all households in the survey.
} 
job location (3.1\%); (2) persons who work at home (5.6\%); (3) workers whose workplace location was not adequately described (this includes all persons commuting to a job outside of the GMR) (4.6\%); (4) commuters who chose bicycle, auto-rickshaw, taxi, or shared ride as their as their main mode (due to the low frequency of such choices) (5.4\%); (5) a small number of workers who claim they commute by two-wheeler or car but do not own such a vehicle (0.3\%). Excluding these persons resulted in 4,958 commuters. ${ }^{14}$ Assumptions made in computing the cost, in-vehicle and out-of-vehicle travel times for modes not chosen are described in the Appendix.

The joint model is estimated using the data for the principal earner in each household. Most households who own a vehicle have only one car or two-wheeler, and it is usually the primary income earner who uses them for commuting. All other sampling details are the same as the commute mode choice models, resulting in a sample of 3,786 households.

\section{Estimation Results}

Tables 4 presents the results of estimating the multinomial logit and mixed logit models and Table 5 the resulting elasticities. ${ }^{15}$ Several results are worthy of comment. The value of travel time, both in-vehicle and walking, is greater than the wage. In model 1, the value of out-of-vehicle travel time (walking time) is 1.2 times the wage; the value of in-vehicle travel time is equal to the wage. This is a common result in mode choice studies in developing countries (Deaton et al. 1987). The high value of walking time is in

\footnotetext{
${ }^{14}$ Approximately $24 \%$ of commuters were dropped. The percent of commuters dropped is approximately the same for all income and education categories; however, commuters with vehicles were less likely to be dropped than those without.

${ }^{15}$ Price and income elasticities are calculated as simulated arc elasticities corresponding to a $50 \%$ increase in rail fare, bus fare, gas price and income, respectively.
} 
part a result of the high cost of bus fares in Mumbai. All travelers in our choice set face the option of walking or taking the bus. For persons for whom these are the only options and who are indifferent between walking and taking the bus, the value of time will equal the cost of taking the bus, divided by the resulting time saving.

Both the value of the income elasticities and own- and cross-price elasticities are extremely similar across models. ${ }^{16}$ Own-price elasticities are highest for bus $(-0.35$ to $-0.45)$ and car $(-0.35$ to -0.38$)$ and lowest for rail $(-0.07$ to -0.08$)$. It should be noted that the cost per km of traveling by rail is much cheaper than the cost of bus service, especially if a monthly pass is purchased. For example, a worker with a one-way commute of $20 \mathrm{~km}$ pays only Rs. 90 per month to commute by rail—less than Rs. 4 per day. The cost per day of commuting $20 \mathrm{~km}$ via bus is, by contrast, Rs. 20. Cross-price elasticities are generally lower than own-price elasticities: for example, the elasticity of the rail modal share with respect to an increase in the bus fare is approximately 0.25 .

Table 6 presents estimation results for the nested logit model of vehicle ownership and commute mode choice and Table 7 the resulting elasticities. The nested logit model includes household characteristics - the number of workers in the household (\# WORKERS), whether there is a child 10 or younger in the household (CHILD), whether the household lives in the suburbs (SUBURB), the years of education of the household head (EDUCATION), and whether the head of household is self-employedas well as time and money costs.

The results of estimating the joint model of vehicle ownership and commute mode choice are generally reasonable. The income elasticity of motor vehicle ownership is

\footnotetext{
${ }^{16}$ This was, to us, somewhat surprising. One motive for estimating mixed logit models is that they admit of a richer set of substitution possibilities than the multinomial logit model (Train 2003).
} 
1.63 for a car and 0.47 for a two-wheeler. These figures are higher than one would find in high income countries, but broadly consistent with findings in developing countries (Kopits and Cropper 2005), although the latter are usually based on country-level panel data. Households with self-employed or more educated household heads are more likely to own a car or two-wheeler. Other results are more puzzling-living in the suburbs, which implies a longer commute, ceteris paribus, is not associated with higher odds of vehicle ownership — nor is having more workers in the household. The own and crossprice elasticities for mode choice are slightly lower than in Tables 4 and 5 for bus and slightly higher for car and two-wheeler.

\section{Implications of Our Estimates for Pollution Control Policies in Mumbai}

What do the estimates in the preceding section imply about the impact of various policies to control pollution from passenger transport? Of the policies we consider, the most effective policy to reduce emissions from passenger vehicles - in terms of the total tons of PM10 reduced - is to convert diesel buses to CNG. Using emissions factors from NEERI (2004) the reduction in PM10 per km from converting a diesel bus to CNG would be $2.76 \mathrm{~g} / \mathrm{km}$. Applying this to a fleet of 3,391 diesel buses that travel approximately 240 million $\mathrm{km} /$ year would result in an emissions reduction of 662 tons of PM10 per year, $14 \%$ of total emissions from transport (ignoring emissions from taxis and threewheelers).

By how much would fares have to rise to cover the cost of these conversions, and to what extent would this erode the emissions reductions calculated in the preceding paragraph? According to NEERI (2004), the capital cost of converting a diesel bus to 
CNG is Rs. 400,000, and the increase in operating and maintenance costs Rs. 80,000 biennially. Assuming that the conversion lasts for 12 years, the annualized cost of the conversion, using an interest rate of 5\%, is Rs. 58,095 . This would raise the cost of a bus ride by Rs. 02 per km. Using an alternate set of figures provided by NEERI suggests a cost of Rs. .07 per km. Fares would have to rise by 5 to $10 \%$ to cover the cost of diesel conversions. The impact of this fare increase on shifts to more polluting modes is, however, small. An increase in the bus fare induces a very small increase in the use of two-wheelers and cars (elasticities of 0.05 and 0.02, respectively), which increases PM10 emissions by only 11 tons per year. The bigger shifts are to rail and walking, which emit no PM10. Hence, at least in Mumbai, the concern that raising bus fares to cover the cost of pollution control will cause a shift to private motor vehicles appears unfounded.

What impact will an increase in the price of gasoline have on PM10 emissions?

Using Table 7 to compute the elasticity of PM10 emissions from transport yields an elasticity of only -0.04 . A doubling of the price of gasoline would reduce emissions by only 4\%, or approximately 198 tons of PM10 per year. This reflects two factors: the elasticity of two-wheeler and car emissions with respect to the price of gas, and the initial shares of two-wheelers and cars in total emissions from transport. According to Table 7, the elasticity of PM10 emissions with respect to the price of gas $=-0.26$ for two-wheelers and -0.38 for cars. ${ }^{17}$ These estimates, however, reflect only adjustments in modal shares and not adjustments in the number of trips made or in trip length. Hence, these

\footnotetext{
${ }^{17}$ Note that the elasticity of PM10 emissions for cars (two-wheelers) with respect to the price of gas $\equiv$ the elasticity of VKTs with respect to the price of gas, assuming that the price of gas does not alter emissions per km.
} 
elasticities represent lower bounds. ${ }^{18}$ The elasticities, however, are in the range of elasticities reported by Johansson and Schipper (1997). The reason that the elasticity of total emissions is so low is because two-wheelers and cars in Mumbai contribute only about $16 \%$ of PM10 emissions from transport. If we were to double the emissions elasticities for cars and two-wheelers, doubling the price of gas would reduce PM10 by about 400 tons per year- 40 percent less than the CNG bus program.

A more effective strategy to control vehicle emissions would be to impose large fees on private vehicle ownership. The income elasticities in Table 7 imply that a 50\% increase in household incomes will increase the proportion of households owning twowheelers from $16.6 \%$ to $20.5 \%$ and the proportion of households owning cars from $5.7 \%$ to $10.4 \%$. Imposing a tax on vehicle ownership equal to $50 \%$ of the purchase price (a "Singaporean" tax) implies that ownership of two-wheelers would increase to only $17.3 \%$ of households, while car ownership would increase to only $6.0 \%$ of households. The elasticity of emissions from transport with respect to a tax on vehicle ownership is -0.10 , over twice the size (in absolute value) of the elasticity of emissions with respect to the price of gasoline.

Without information about the cost of air pollution control equipment for cars and two-wheelers, we are unable to calculate the optimal gasoline tax for Mumbai. We can, however, provide a rough estimate of the net benefits of a program to convert BEST buses to CNG. As indicated above, the net reduction in PM10 emissions from such a program would be on the order of 650 tons per year. To estimate the health benefits of

\footnotetext{
${ }^{18}$ A referee suggested that we increase these elasticities to allow for adjustments in number of trips and trip length. This could be done using data from studies in high income countries (see, e.g., Johansson and Schipper 1997); however, the fraction of VKTs attributable to work trips is much higher in Mumbai (approximately $2 / 3$ ) than in the U.S., where it is approximately $1 / 3$, hence it is likely to be more difficult to adjust the number of trips made and their distance in Mumbai than in the U.S.
} 
such a reduction we rely on air quality modeling performed as part of the Urban Air Quality Management Strategy for Mumbai (World Bank 1997) conducted in the mid 1990s. The impact of a 650 ton reduction in PM10 on mortality, conservatively calculated, is to reduce deaths in Mumbai by about 100 per year. This is based on daily time series studies relating PM10 to mortality that assume a $10 \mu \mathrm{g} / \mathrm{m}^{3}$ reduction in PM10 will reduce daily deaths by about $1 \%$. This is an extremely conservative estimate of the health benefits of reducing PM10, as it ignores the long-term impacts of particulate exposure on mortality, as well as the impacts of PM reductions on morbidity.

A rough calculation of the cost per life saved, based on the above estimate, suggests a cost of $1,970,000$ Rs. $\left(=58,095^{*} 3,391 / 100\right)$, or approximately $\$ 46,000$ USD. This is much lower than estimates of the values of a statistical life for India (Simon et al. 1999, Shanmugam 1997), which range from 6 to 15 million Rs. However, our upper bound estimate of the cost per life saved is greater than the estimate of foregone earnings in Mumbai (250,000 Rs.) estimated by URBAIR (World Bank 1997). This suggests that converting diesel buses to CNG may indeed pass the benefit-cost test.

\section{Conclusions}

This paper examined the impacts of measures to reduce emissions from buses, cars and two-wheelers in Mumbai, India. We have considered three possible policies: conversion of diesel buses to $\mathrm{CNG}$, an increase in the price of gasoline and a tax on vehicle ownership.

Our results suggest that the most effective policy to reduce emissions from passenger vehicles - in terms of the total number of tons of PM10 reduced - is to convert 
diesel buses to CNG. The conversion of 3,391 diesel buses to CNG would result in an emissions reduction of 663 tons of PM10 per year, 14\% of total emissions from transport. Indeed, the bus conversion program passes the cost-benefit test.

In contrast, our results suggest the elasticities of emissions from transport with respect to a gasoline tax and a tax on vehicle ownership are -0.04 and -0.10 respectively. As a consequence, it would take substantial increases in the gasoline tax or vehicle ownership tax to produce reductions in emissions similar to the bus conversion program. This is true even we double these elasticities to allow for adjustments in trip length and in the number of trips made, adjustments that our data do not allow us to capture. It should be emphasized that this finding primarily reflects the small share of two-wheelers and cars in the Mumbai vehicle fleet. Our estimate of the elasticity of PM10 emissions (VKTs) with respect to the price of gasoline are -0.38 for cars, and -0.26 for twowheelers, estimates that agree with the international literature (Johansson and Schipper, 1997). The low elasticity of total vehicle emissions with respect to the price of gas reflects the fact that cars and two-wheelers account for only $16 \%$ of PM10 emissions from transport in Mumbai.

Would our results generalize to other Indian cities? It seems plausible that the he cost per ton of PM10 reduced should be approximately the same in other large Indian cities as in Mumbai, assuming that emissions per $\mathrm{km}$ and VKTs per bus are roughly the same in both places. The benefits per ton of PM10 reduced will depend on the impact of reducing a ton of emissions from buses on ambient air quality and will vary directly with city population, since clean air is a public good. Thus, drawing conclusions about whether converting buses to $\mathrm{CNG}$ passes the benefit-cost test requires further analysis. 
In terms of total PM10 reduced, the effectiveness of a gas tax v. a program to convert buses to CNG could be different in other Indian cities. In Delhi, for example, it has been estimated that two-wheelers contribute half of the PM10 produced by transport (Society of Indian Automobile Manufacturers, 2004). Assuming that the elasticity of VKTs with respect to the price of gas is roughly the same in the two cities, the gas tax would have a larger impact on PM10 in Delhi than in Mumbai. 
Table1: Share of Vehicle Usage and PM10 Emissions From Transport Sector by Mode

\begin{tabular}{lccccccc}
\hline \hline & Two & Three & & & \multicolumn{3}{c}{ Other } \\
& Diesel & \\
& wheeler & wheeler & Car & Taxi & Best Bus & vehicles & Total \\
\hline Number of vehicles (2001) & 440,517 & 101,914 & 344,870 & 62,447 & 3,391 & 76,424 & $1,029,563$ \\
Share of Vehicle km (2002) & $20 \%$ & $16 \%$ & $29 \%$ & $14 \%$ & $4 \%$ & $17 \%$ & $100 \%$ \\
NEERI Emission factors (g/km) & 0.21 & 0.21 & 0.27 & 0.27 & 3 & 3 & - \\
Share of PM10 (2002) & $5 \%$ & $4 \%$ & $10 \%$ & $5 \%$ & $14 \%$ & $63 \%$ & $100 \%$ \\
\hline
\end{tabular}


Table 2: Main Mode to work by Household Income (\%)

\begin{tabular}{lcccccc}
\hline \hline & $<5 \mathrm{k}$ & $5-7.5 \mathrm{k}$ & $7.5-10 \mathrm{k}$ & $10-20 \mathrm{k}$ & $>20 \mathrm{k}$ & All HHs \\
\hline On foot & 61 & 50 & 41 & 30 & 15 & 44 \\
Bicycle & 6 & 4 & 2 & 1 & 0 & 3 \\
Train & 16 & 23 & 26 & 26 & 21 & 23 \\
Public Bus & 15 & 17 & 18 & 16 & 13 & 16 \\
Auto-Rickshaw & 1 & 1 & 1 & 3 & 3 & 2 \\
Taxi & 0 & 0 & 0 & 0 & 1 & 0 \\
Own Two-Wheeler & 1 & 4 & 10 & 18 & 21 & 9 \\
Own Car & 0 & 0 & 0 & 4 & 24 & 3 \\
Other's car & 0 & 0 & 0 & 0 & 1 & 0 \\
Other & 0 & 1 & 1 & 1 & 3 & 1 \\
Total & 100 & 100 & 100 & 100 & 100 & 100 \\
\hline
\end{tabular}


Table 3: Modal Share by Purpose of Trip

\begin{tabular}{|c|c|c|c|c|c|c|c|c|}
\hline & Work & Shopping & School & $\begin{array}{c}\text { Social } \\
\text { Visit }\end{array}$ & $\begin{array}{c}\text { Enter- } \\
\text { tainment }\end{array}$ & $\begin{array}{c}\text { Health } \\
\text { Care }\end{array}$ & Personal Business & $\begin{array}{c}\text { Avg., All } \\
\text { Trips }\end{array}$ \\
\hline$\overline{\text { On foot }}$ & 45.1 & 82.2 & 55.5 & 52.4 & 51.6 & 66.9 & 47.9 & 52.5 \\
\hline Bicycle & 3.5 & 0.4 & 0.4 & 0.4 & 0.0 & 0.8 & 1.2 & 2.2 \\
\hline Train & 20.9 & 1.5 & 15.3 & 13.8 & 3.5 & 1.2 & 13.2 & 15.4 \\
\hline Public Bus & 15.1 & 6.2 & 22.3 & 13.1 & 16 & 12.8 & 18.3 & 14.6 \\
\hline Auto-Rickshaw & 2.1 & 5.4 & 3.3 & 7.6 & 7.0 & 13.2 & 6.7 & 4.3 \\
\hline Taxi & 0.3 & 1.4 & 0.1 & 6.3 & 3.5 & 3.1 & 0.8 & 1.1 \\
\hline Two-Wheeler & 8.6 & 2.5 & 2.3 & 3.1 & 8.0 & 1.2 & 8.3 & 6.4 \\
\hline Own Car & 3.2 & 0.4 & 0.3 & 1.6 & 4.3 & 0.4 & 3.3 & 2.4 \\
\hline Other's car & 0.4 & 0.2 & 0.1 & 1.5 & 6.2 & 0.4 & 0.4 & 0.6 \\
\hline Other & 0.8 & 0.0 & 0.3 & 0.3 & 0.0 & 0.0 & 0.0 & 0.5 \\
\hline Total & 100 & 100 & 100 & 100 & 100 & 100 & 100 & 100 \\
\hline$\%$ of Total Trips & 47.6 & 15.5 & 9.4 & 8.6 & 4.9 & 3.3 & 10.4 & 100 \\
\hline
\end{tabular}


Table 4: Multinomial Logit and Mixed Logit Models

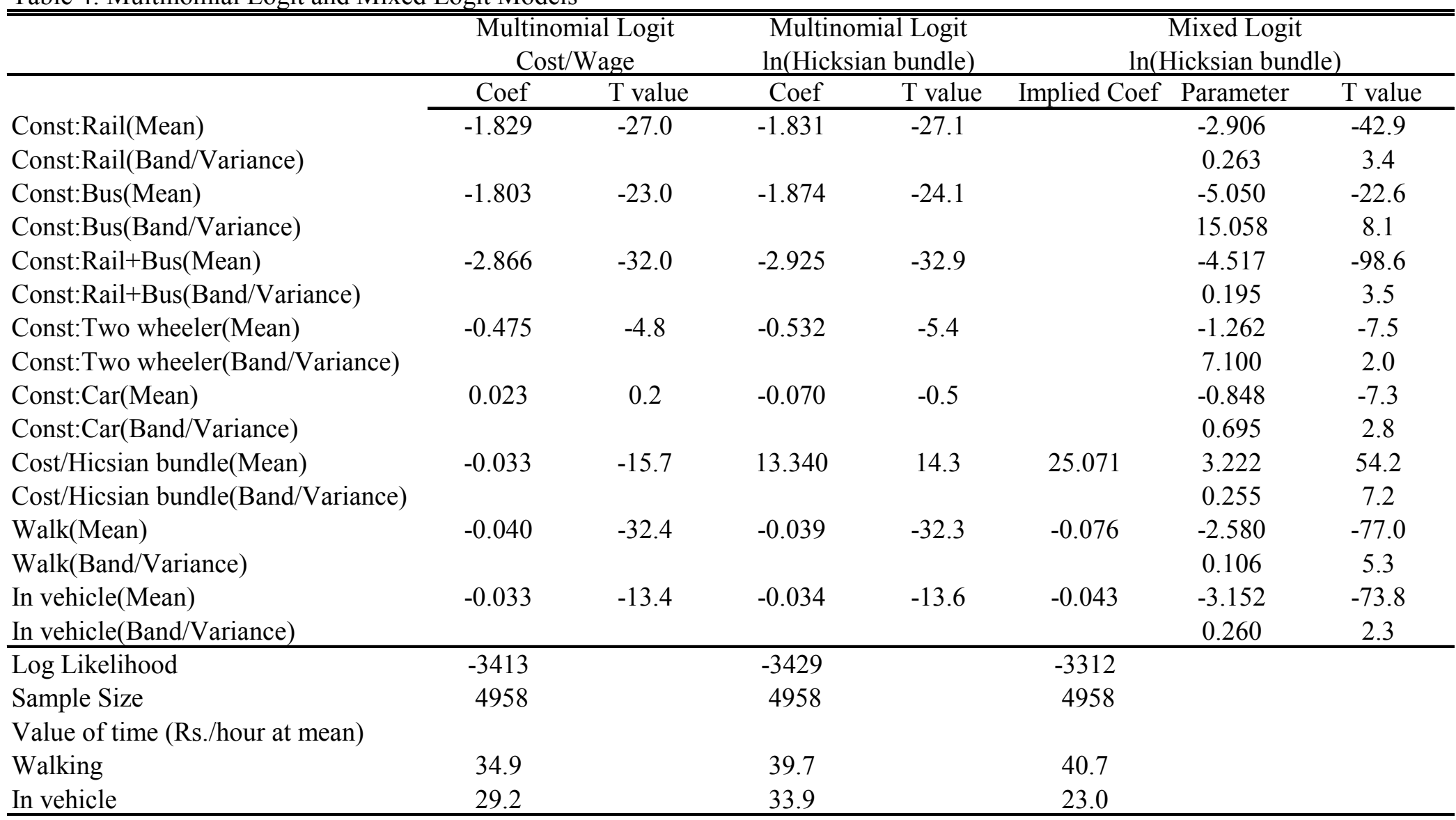


Table 5: Own-Price and Cross-Price Elasticties from Table 4

\begin{tabular}{|c|c|c|c|c|c|}
\hline & & \multicolumn{4}{|l|}{ Increase in } \\
\hline & & Rail fare & Bus fare & Gas price & Income \\
\hline \multirow{6}{*}{ 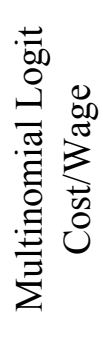 } & Walk & 0.01 & 0.08 & 0.02 & -0.08 \\
\hline & Rail & -0.08 & 0.26 & 0.05 & -0.18 \\
\hline & Bus & 0.06 & -0.45 & 0.06 & 0.28 \\
\hline & Rail+Bus & -0.07 & -0.19 & 0.06 & 0.11 \\
\hline & Two Wheeler & 0.01 & 0.04 & -0.22 & 0.11 \\
\hline & Car & 0.01 & 0.03 & -0.36 & 0.26 \\
\hline \multirow{6}{*}{ 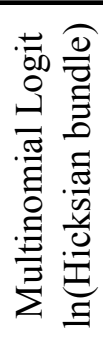 } & Walk & 0.01 & 0.08 & 0.02 & -0.07 \\
\hline & Rail & -0.07 & 0.25 & 0.05 & -0.17 \\
\hline & Bus & 0.05 & -0.42 & 0.06 & 0.25 \\
\hline & Rail+Bus & -0.07 & -0.17 & 0.06 & 0.08 \\
\hline & Two Wheeler & 0.01 & 0.04 & -0.21 & 0.11 \\
\hline & Car & 0.00 & 0.03 & -0.35 & 0.25 \\
\hline \multirow{6}{*}{ 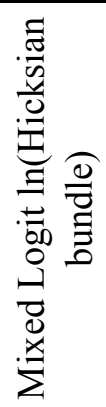 } & Walk & 0.01 & 0.06 & 0.02 & -0.07 \\
\hline & Rail & -0.07 & 0.25 & 0.05 & -0.18 \\
\hline & Bus & 0.04 & -0.35 & 0.05 & 0.21 \\
\hline & Rail+Bus & -0.07 & -0.26 & 0.06 & 0.18 \\
\hline & Two Wheeler & 0.01 & 0.03 & -0.18 & 0.10 \\
\hline & Car & 0.01 & 0.03 & -0.38 & 0.30 \\
\hline
\end{tabular}


Table 6: Nested Logit Model of Vehicle Ownership and Mode Choice

\begin{tabular}{|c|c|c|}
\hline Variables & Coefs. & T-value \\
\hline Constant: Rail & -1.01 & -11.47 \\
\hline Constant: Bus & -1.09 & -10.45 \\
\hline Constant: Rail+Bus & -1.73 & -11.54 \\
\hline Constant: 2-wheeler & -0.14 & -1.62 \\
\hline Constant: Car & -0.21 & -2.09 \\
\hline Constant: Own 2-wheeler & -3.23 & -10.50 \\
\hline Constant: Own Car & -3.78 & -5.05 \\
\hline Constant: Own Both & -5.13 & -5.29 \\
\hline Walking time & -0.02 & -11.93 \\
\hline In-vehicle time & -0.02 & -8.90 \\
\hline \#workers*Own 2-wheeler & -0.09 & -1.29 \\
\hline \#workers*Own Car & -0.25 & -1.88 \\
\hline \#workers*Own Both & -0.26 & -1.47 \\
\hline Child*Own 2-wheeler & 0.27 & 2.50 \\
\hline Child*Own Car & 0.05 & 0.23 \\
\hline Child*Own Both & 0.17 & 0.60 \\
\hline Suburb*Own 2-wheeler & -0.61 & -5.49 \\
\hline Suburb*Own Car & -0.62 & -2.78 \\
\hline Suburb*Own Both & -0.70 & -2.01 \\
\hline Years of Edu*Own 2-wheeler & 0.14 & 7.37 \\
\hline Years of Edu*Own Car & 0.28 & 6.92 \\
\hline Years of Edu* Own both & 0.27 & 5.37 \\
\hline Business Owner*Own 2-wheeler & 1.23 & 11.16 \\
\hline Business Owner*Own Car & 0.98 & 4.47 \\
\hline Business Owner* Own Both & 1.73 & 4.62 \\
\hline Hicksian bundle & 7.63 & 18.34 \\
\hline Inclusive Value: None & 0.57 & 11.75 \\
\hline Inclusive Value: Own 2-wheeler & 0.65 & 10.40 \\
\hline Inclusive Value: Own Car & 0.39 & 9.01 \\
\hline Inclusive Value: Own Both & 0.69 & 4.17 \\
\hline Log likelihood & -4412 & \\
\hline Sample size & 3724 & \\
\hline \multicolumn{3}{|l|}{ Value of time (Rs./hour at mean) } \\
\hline Walking & 64 & \\
\hline In vehicle & 59 & \\
\hline
\end{tabular}


Table 7: Elasticities from Model of Vehicle Ownership and Mode Choice (table 6)

\begin{tabular}{clccccccc}
\hline \hline & \multicolumn{4}{c}{ Commute Mode } & \multicolumn{3}{c}{ Ownership } \\
\hline Increase in & Walk & Rail & Bus & Rail+Bus & MTW & Car & MTW & Car \\
Rail fare & 0.01 & -0.05 & 0.04 & -0.05 & 0.01 & 0.00 & 0.00 & 0.00 \\
Bus fare & 0.06 & 0.15 & -0.33 & -0.03 & 0.05 & 0.02 & 0.02 & 0.01 \\
Gas price & 0.02 & 0.07 & 0.08 & 0.08 & -0.26 & -0.38 & -0.12 & -0.10 \\
Income & -0.15 & -0.21 & 0.03 & -0.12 & 0.50 & 1.80 & 0.47 & 1.63 \\
Registration fee & 0.07 & 0.06 & 0.11 & 0.07 & -0.39 & -0.90 & -0.43 & -0.99 \\
\hline
\end{tabular}




\section{Appendix. Construction of Variables Used in Commute Mode Choice Models}

\section{Out-of-vehicle travel time:}

- Walking: Distance from home to job/0.067 (Equivalent to speed of 4km/hour)

- Rail: Distance to nearest rail station (from home and from job)/0.067

- Bus: Answer to "How far is the nearest bus stop?" (from work and from home) from household survey. (Midpoint of the selected range is used.)

- Two-wheeler: 0

- Car: 0

In-vehicle travel time:

- Walking: 0

- Rail, Bus, Two-wheeler, Car: Distance traveled/Average speed of the mode by distance category, short $(1-5 \mathrm{~km}) /$ medium $(5-10 \mathrm{~km}) /$ long $(>10 \mathrm{~km})$. [Average speed of mode calculated for each distance category using (actual in vehicle time)/(distance to work) for persons who chose that mode. Those who traveled less than $1 \mathrm{~km}$ is excluded to from the estimation of travel speed because of the relatively large error involved in distance traveled.]

\section{Money cost:}

- Walking : 0

- Rail, Bus: Calculated based on the fare tables and distance traveled. The fare tables are taken from http://www.indianrail.gov.in/ (rail) and the Mumbai Metropolitan Region Development Authority (bus).

- Two-wheeler, Car: Gas price (Rs. 37.74 /litre)/Gas mileage (24km/litre for twowheeler and $10 \mathrm{~km} /$ litre for car)*Distance

The distance from home to job is estimated as the distance between the worker's home (whose location is geo-reference in the survey) and his approximate work location. The work location is approximated by the centroid of the intersection of the section and pin code in which the job is located. ${ }^{19}$ The distances to rail stations from the home and workplace have been calculated using the geo-referenced locations of train stations. The travel distance for rail is the network distance, calculated from actual rail network data.

The wage per minute is calculated as follows:

- Personal income per month/206/60 for full time workers (assuming 8 hours per day, 6 days per week)

\footnotetext{
${ }^{19}$ If the pin code (section) of the work place is unavailable, the centroid of the section (pin code) is used.
} 
- Personal income per month/103/60 for non-full time worker (assuming they work half time)

\section{Ownership cost of vehicles:}

The price of a new, entry level compact car is Rs. 220,000 and the price of a new motorbike Rs. 32,000. One-time registration fees are Rs.8,500 for a car and Rs.1,500 for a motorbike. Assuming straight-line depreciation over 10 years for car and 5 years for bike, the depreciation cost is $22,850 /$ year for a car and 6,700/year for a bike. The opportunity cost of capital is assumed to be $5 \%$ per year, applied to the remaining value of the vehicle each year. Averaging these costs over the usable life of the vehicle and adding comprehensive insurance costs gives us a monthly ownership cost of Rs. 3136 for a car and Rs. 834 for a motorbike. 


\section{References}

Baker, Judy, Rakhi Basu, Maureen Cropper, Somik Lall and Akie Takeuchi, (2005). "Urban Poverty and Transport: The Case of Mumbai," Policy Research Working Paper 3693.

Burningham, Sally (2005). Personal Communication, June 6.

Deaton, Angus et al. (1987). "The Demand for Personal Travel in Developing Countries." Infrastructure and Urban Development Papers, Report INU 1, World Bank, Washington, DC.

Eskeland, Gunnar (1994). "A Presumptive Pigovian Tax: Complementing Regulation to Mimic an Emissions Fee,” World Bank Economic Review, 8(1):373-394.

Fullerton, Don and Sarah West (1999). "Can Taxes on Cards and on Gasoline Mimic and Unavailable Tax on Emissions?” NBE Working Paper 7059.

Johansson, Olof and Lee Schipper (1997). "Measuring the Long-Run Fuel Demand for Cars," Journal of Transport Economics and Policy, 31(3):277-292.

Kopits, Elizabeth and Maureen Cropper (2005). "Traffic Fatalities and Economic Growth," Accident Analysis and Prevention, 37(1):169-178.

National Environmental Engineering Research Institute (2004). Particulate Matter $\underline{\text { Reduction Action Plan for Greater Mumbai. }}$

Reddy, B. Sudhakara (2000). "Urban Transportation in India: A Tale of Two Cities," Energy for Sustainable Development, 4(1): 65-76.

Shanmugam, K. R. (1997). "Compensating Wage Differentials for Work Related Fatal and Injury Accidents," The Indian Journal of Labor Economics, 40(2).

Simon, Nathalie, Maureen L. Cropper, Ann Alberini and Seema Arora (1999). "Valuing Mortality Reductions in India. A Study of Compensating Wage Differentials." World Bank. Policy Research Working Paper 2078.

Society of Indian Automobile Manufacturers (2004). “Automobile Industry’s Views for Control of Emissions from Mobile Sources." New Delhi. Mimeo.

Swait, Joffrey and Gunnar S. Eskeland (1995). "Travel Mode Substitution in São Paulo. Estimates and Implications for Air Pollution Control." World Bank. Policy Research Working Paper 1437.

Train, Kenneth (2003). Discrete Choice Methods with Simulation. Cambridge, Cambridge University Press. 
World Bank (1997). Urban Air Quality Management Strategy in Asia. Greater Mumbai Report. Jitendra J. Shah and Tanvi Nagpal Eds. Washington, DC.

World Bank (2005). For a Breath of Fresh Air: Ten Years of Progress and Challenges in Urban Air Quality Management in India. Environment and Social Development Unit, South Asia Region. 